\title{
PHYSICAL PROPERTIES OF HULLED PEANUTS AND
} KERNELS

\section{Ghanem T.H.*}

\section{El-Said Shetawy ** A.K.Zaalouk** \\ ABSTRACT}

This study was carried out to evaluate some physical properties for two different varieties of peanuts, namely: Ismailial "Is1" and Giza5 "G5" such as length, width, shell thickness, weight, volume, percentage of void space, and density for kernels and Hulls. Hulled peanuts and kernels can be classified into three classes i.e. small, medium and large based on average values of their characteristics and associated standard deviation. Several empirical equations based on a large number of measurements for volume of an individual hull and kernel, bulk density are presented.

The main objective of the present study is to evaluate some physical properties of two different Egyptian verities that affect design and development of; precision planting, grading, drying, fraying and storage machines.

\section{INTRODUCTION}

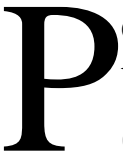

eanut (Arachis hypogea L.) is one of the most important oil bearing seeds. In Egypt the cultivated area is about $3.024 \times 10^{6}$ ha, (FAO 2008), that produced about $15.12 \times 10^{6}$ tons. In the last few years there was a marked deterioration in quality of peanut grown in Egypt, due to high incidence of aflatoxin contamination and increased percentage of immature seeds. The growth of mould on the peanut is the indirect result of too much moisture for unsafe storage. To control the fungal attack on the peanut it was recommended by Hummeida and Ismail (1989) that the moisture content of the peanuts should be maintained below $8 \%$ w.b. However, in storage is the moisture content controlled by circulation of air and control of the relative humidity.

Mohsenin (1970) reported that the physical properties of materials such as shape, size, volume, and surface area are important in many problems associated with design or development of a specific machine, analysis of the behavior of the product in handling, stress distribution in material

\footnotetext{
* Associate Prof., Agric. Eng.. Fac. of Agric., Al-Azhar Univ. **Lect. Agric. Eng. Dept. Fac. of Agric., Al-Azhar Univ.
} 
conveying of solid materials by air or water is the assumption for the shape of the material. He also added that accurate estimation of the frontal area and the related diameters are essential for determination of terminal velocity, drag coefficient and Renold's number.

Chakraverty (1972) defined the sphericity of grain as the ratio of surface area of sphere having the same volume as that of the particle to the surface area of the particle.

El-Raie (1987) studied some physical characteristics of shelled corn related to mechanical separation i.e. shape, size, moisture content, length, width, thickness, volume, geometric diameter, sphericity, area of flate surface and area of the transverse one of individual seeds. He suggested a set of equations that can be used for predicting some physical characteristics of corn with reasonable accuracy.

Matthews (1991) reported that, for determining grain size from grain weight, the density of individual grain is required. This can be measured by means of picnometer or fluid displacement techniques. He stated that the void ratio can be determined in terms of the bulk density. He also reported that the grain surface area is very important in determining the volumetric and gravimetric heat transfer coefficients for heat transfer applications.

Akcali and Onur (1990) described peanut geometrically as being composed of a cylinder of a finite length in the middle and two hemispheres of the same cylinder radius in the ends. They added that one advantage of this model is that applies equally well to shell and kernels.

Due to the lack of information about physical properties of new created varieties of hulled peanuts and their kernels, and owing to losses during harvesting, handling and the marked deterioration in quality of peanuts as a result of unsafe storage.

This work was carried out to study some physical properties of two different Egyptian verities that affect design and development of, precision planting, grading, drying and storage such as mass, size, volume, void ratio, density, bulk density of both kernels and hulls. 
This work was carried out to determine some physical properties of two common Egyptian varieties of peanuts namely: Ismailia1 "Is1" and Giza5 "G5".

\section{Measuring instrumentations:}

1- Digital vernire caliper, with accuracy of $0.01 \mathrm{~mm}$ was used for measuring length, diameter, and shell thickness.

2- Electrical balance: made in Japan, Sartorius type , accuracy $0.0001 \mathrm{~g}$.

3- Electrical oven with forced hot air circulation no. 299 of maximum temperature of $300{ }^{\circ} \mathrm{C}$ made in Germany.

4- The moisture content for peanut pods (shells and kernels) is evaluated according to the ASAE standards (1994) i.e., oven dried at $130{ }^{\circ} \mathrm{C}$ for 6 hours.

\section{Experimental procedure:}

1 Hull and kernel dimensions: Fig.(1) shows principal hull and kernel dimensions .These dimensions were measured using a digital vernire caliper. A large number of hulls and kernels were measured for both varieties tested. Physical characteristics can be utilized effectively in design or development of devices and their operations or in analyzing the behavior of product handling and sieving operations.

Peanuts and kernels were also classified into three classes by calculating
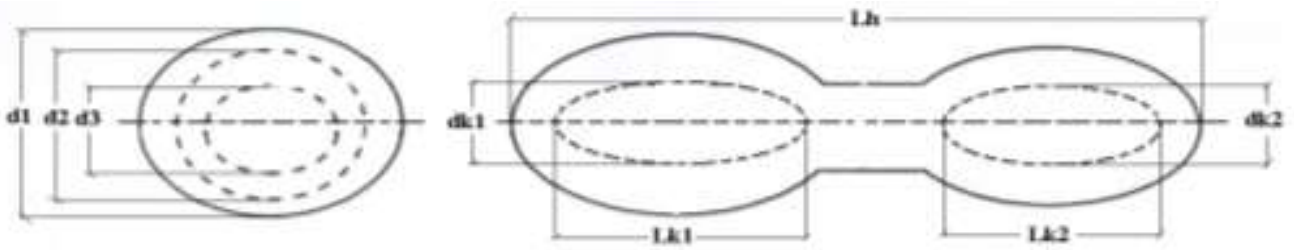

Fig. (1) Principal hull and kernel dimensions.

the average " $x$ " of dimension $\mathrm{x}$ and the associated standard deviation " $\sigma_{x}$ ” as follows:

$$
\begin{gathered}
\bar{x}=\sum_{i=1}^{n} x_{i} / n \ldots \ldots . . \\
\sigma_{x}=\sqrt{\frac{\sum_{i=1}^{n}\left(x_{i}-\bar{x}\right)^{2}}{n} .}
\end{gathered}
$$


Then, small, medium and large sizes of both peanuts and kernels can be defined as their specific $\mathrm{x}$ dimension that satisfies the following inequalities, respectively:

$$
\begin{aligned}
& x<\bar{x}-\sigma_{x} \\
& \bar{x}-\sigma_{x}<x<\bar{x}+\sigma_{x} \\
& x>\bar{x}+\sigma_{x} \ldots \ldots \ldots \ldots
\end{aligned}
$$

This classification is one of the necessary input data for design of grading machinery and it can be used as a quality index.

The following relation can be used for calculating the geometric diameter (Mohsenin 1970):

$$
d_{g}=(a b c)^{1 / 3}
$$

2 Hull and kernel surface area: The actual surface area of a single hull or kernel "a" in $\mathrm{mm}^{2}$ was measured by binding a sticky tape firmly around the individual object, cutting it till it takes the same profile of that object, then releasing the tape, pasting it on a white paper. Then, the surface area of an individual hull or kernel is determined using the approximation of Simpson's rule.

3 Volume of individual hull or kernel: Volume was evaluated as reported by Akcali and Onur (1990) using suitable filling material and subtracting the volume of (the hull or kernel+ filling material) from that occupied with the filling material using a small graduate cylinder of 20 $\mathrm{cm}^{3}$ for hulls and $5 \mathrm{~cm}^{3}$ for kernels. They also assumed peanut hull or kernel geometrically as being composed of a cylinder of a finite length in the middle and two hemispheres of the same cylinder radius in the ends. They added that the volume of a mixed sample " $\mathrm{V}_{\mathrm{m}}$ " in $\mathrm{mm}^{3}$ can be determined as follows:

$$
V_{m}=[(d / 3)+(L-d) / 2] \pi d^{2} N / 2
$$

Where $\mathrm{L}, \mathrm{d}$ are average sample length and diameter ,respectively; and $\mathrm{N}$ is the number of hulls or kernels of the tested sample.

In the present work, we applied the same model for calculating the volume of an individual hull or kernel "V" assuming that " $\mathrm{L}$ " is an average of an individual hull or kernel length, " $\mathrm{d}$ " is an average is an average of an individual hull or kernel diameter ; and $\mathrm{N}=1$.

The $16^{\text {th }}$. Annual Conference of the Misr Society of Ag. Eng., 25 July, 2009 
4 Density $\rho$ and bulk density $\rho_{b}$ of hulls and kernels: Hulls or kernels density " $\rho$ " in $\mathrm{g} / \mathrm{mm}^{3}$ was determined by measuring the actual volume of hulls or kernels using the previous technique of filling material, then dividing the mass by the volume of the same sample. The bulk density " $\rho_{b}$ " in $g / \mathrm{mm}^{3}$ was also evaluated by dividing the mass of a quantity of hulls or kernels by its volume, which was measured by using a constant volume cylinder.

The void space ratio " $\varepsilon$ "was also evaluated according to Matthews (1991) as follows:

$$
\varepsilon=1-\rho \mathrm{b} / \rho
$$

This characteristic affecting air flow, heat and mass transfer, occupied volumes during handling, drying in backed beds and storage of peanut hulls or kernels.

\section{RESULTS AND DISCUSSIONS}

1.Hull and Kernel dimensions: principal dimensions of both hull and kernel are shown in Fig.(1). Table (1) shows minimum, maximum and average values of length, diameter of hulls ,kernels, shell thickness and their standard deviations for both studied varieties. Fig.(2) through (6) show the frequency distribution of averages of all studied dimensions for all varieties tested respectively. Peanuts and kernels were also classified into three classes i.e. small, medium and large size of hulled peanuts and kernels for all varieties tested Table (2).

This classification is one of the necessary input data for sieving, grading machinery and it can be used as a quality index.

2 Hull and kernel surface area: The surface area of hulls and kernels were evaluated experimentally. Correlation between hulls or kernels surface areas "a " in $\mathrm{mm}^{2}$ and their weights " $\mathrm{w}$ " in grams for both studied varieties were found to satisfy a linear form as follows:

\section{Hulled peanuts:}

For SI1 variety: $\quad \mathrm{a}=725.72 \mathrm{w}+309.38 \quad \mathrm{R}^{2}=0.77$

For G5 variety: $\quad \mathrm{a}=600.48 \mathrm{w}+748.33 \quad \mathrm{R}^{2}=0.56$

\section{Peanuts Kernel:}

For SI1 variety: $\quad \mathrm{a}=460.13 \mathrm{w}+178.77 \quad \mathrm{R}^{2}=0.67$

For G5 variety: $\quad \mathrm{a}=455.3 \mathrm{w}+163.94 \quad \mathrm{R}^{2}=0.69$

It is clear that the surface area $d$ increased by 725.72 and $600.48 \mathrm{~mm}^{2}$ for The $16^{\text {th }}$. Annual Conference of the Misr Society of Ag. Eng., 25 July, 2009 
Table (1): Minimum, maximum and average values, standard deviation of hull length $L_{h}$, diameters $d_{1}, d_{2}, d_{3}$ geometric mean $d g$ shell thickness $t$, kernel diameters $d_{k 1}, d_{k 2}$ and kernels lengths $\mathbf{L}_{\mathbf{k} 1, \mathbf{L} \mathbf{k} 2}$.

\begin{tabular}{|c|c|c|c|c|c|}
\hline variety & Dimension & Min. & Max. & Avg. & St. dev. \\
\hline \multirow{12}{*}{ SI1 } & $\mathrm{w}_{\mathrm{h}} \quad$ "g" & 1.15 & 3.15 & 2.345 & 0.459 \\
\hline & $\mathrm{L}_{\mathrm{h}}$ "mm" & 31.76 & 49.68 & 39.77 & 3.76 \\
\hline & $\mathrm{d}_{1} \quad$ "mm" & 13.45 & 19.95 & 15.95 & 1.38 \\
\hline & $\mathrm{d}_{2} \quad$ "mm" & 12.11 & 16.30 & 14.39 & 1.42 \\
\hline & $\mathrm{d}_{3} \quad$ "mm" & 7.97 & 14.47 & 12.38 & 1.23 \\
\hline & $\mathrm{dg}$ "mm" & 11.69 & 16.15 & 14.23 & 0.981 \\
\hline & $\mathrm{t}$ "mm" & 0.72 & 1.38 & 1.17 & 0.28 \\
\hline & $\mathrm{W}_{\mathrm{k}} \quad$ "g" & 0.8374 & 1.2838 & 1.0240 & 0.1619 \\
\hline & $\mathrm{d}_{\mathrm{k} 1}$ "mm" & 6.39 & 10.66 & 9.05 & 2.0 \\
\hline & $\mathrm{d}_{\mathrm{k} 2}$ "mm" & 7.72 & 10.37 & 9.4 & 2.42 \\
\hline & $\mathrm{L}_{\mathrm{k} 1}$ "mm" & 16.79 & 23.63 & 19.21 & 1.07 \\
\hline & $\mathrm{L}_{\mathrm{k} 2} \quad$ "mm" & 15.45 & 22.48 & 18.64 & 1.02 \\
\hline \multirow{12}{*}{ G5 } & $\mathrm{w}_{\mathrm{h}}$ "g" & 1.83 & 3.55 & 2.844 & 0.438 \\
\hline & $\mathrm{L}_{\mathrm{h}}$ "mm" & 33.63 & 47.94 & 39.81 & 3.83 \\
\hline & $\mathrm{d}_{1} \quad$ "mm" & 16.01 & 19.63 & 17.48 & 1.31 \\
\hline & $\mathrm{d}_{2} \quad$ "mm" & 12.23 & 18.87 & 15.74 & 1.19 \\
\hline & $\mathrm{d}_{3} \quad$ "mm" & 9.81 & 15.64 & 13.62 & 1.45 \\
\hline & $\mathrm{dg}$ "mm" & 11.44 & 16.95 & 15.61 & 1.124 \\
\hline & t "mm" & 0.55 & 1.66 & 1.24 & 0.30 \\
\hline & $\mathrm{w}_{\mathrm{k}} \quad \mathrm{g} "$ & 1.0237 & 1.3099 & 1.1691 & 0.1106 \\
\hline & $\mathrm{d}_{\mathrm{k} 1}$ "mm" & 8.29 & 12.63 & 10.2 & 1.74 \\
\hline & $\mathrm{d}_{\mathrm{k} 2}$ "mm" & 7.14 & 12.0 & 9.92 & 1.61 \\
\hline & $\mathrm{L}_{\mathrm{k} 1}$ "mm" & 17.33 & 23.68 & 19.71 & 1.16 \\
\hline & $\mathrm{L}_{\mathrm{k} 2}$ "mm" & 17.0 & 22.58 & 19.38 & 1.03 \\
\hline
\end{tabular}

Table (2):Size classification of the hulled peanuts and kernells.

\begin{tabular}{|c|c|l|c|c|c|}
\hline $\begin{array}{c}\text { Peanuts } \\
\text { State }\end{array}$ & Var. & Dimension & $\begin{array}{c}\text { Small-size } \\
\mathbf{m m}\end{array}$ & $\begin{array}{c}\text { Medium-size } \\
\mathbf{m m}\end{array}$ & $\begin{array}{c}\text { Large- } \\
\text { size } \\
\mathbf{m m}\end{array}$ \\
\hline $\boldsymbol{I}=-$ & Is1 & Length & $\mathrm{L}_{\mathrm{H}}<35.91$ & $35.91 \leq \mathrm{L}_{\mathrm{H}} \leq 43.43$ & $\mathrm{~L}_{\mathrm{H}}>43.43$ \\
\hline
\end{tabular}

The $16^{\text {th }}$. Annual Conference of the Misr Society of Ag. Eng., 25 July, 20091603 


\begin{tabular}{|c|c|c|c|c|c|}
\hline & & Diameter & $\mathrm{d}_{\mathrm{H}}<13.25$ & $13.25 \leq \mathrm{d}_{\mathrm{H}} \leq 15.21$ & $\mathrm{~d}_{\mathrm{H}}>15.21$ \\
\hline & & $\begin{array}{l}\text { Shell } \\
\text { thickness }\end{array}$ & $\mathrm{t}_{\mathrm{H}}<0.85$ & $0.85 \leq \mathrm{t}_{\mathrm{H}} \leq 1.32$ & $\mathrm{t}_{\mathrm{H}}>1.32$ \\
\hline & G5 & Length & $\mathrm{L}_{\mathrm{H}}<37.16$ & $37.16 \leq \mathrm{L}_{\mathrm{H}} \leq 42.98$ & $\mathrm{~L}_{\mathrm{H}}>42.98$ \\
\hline & & Diameter & $\mathrm{d}_{\mathrm{H}}<14.49$ & $14.49 \leq \mathrm{d}_{\mathrm{H}} \leq 16.74$ & $\mathrm{~d}_{\mathrm{H}}>16.74$ \\
\hline & & $\begin{array}{l}\text { Shell } \\
\text { thickness }\end{array}$ & $\mathrm{t}_{\mathrm{H}}<0.99$ & $0.99 \leq \mathrm{t}_{\mathrm{H}} \leq 1.47$ & $\mathrm{t}_{\mathrm{H}}>1.47$ \\
\hline & Is1 & Length & $\mathrm{L}_{\mathrm{k}}<17.03$ & $17.03 \leq \mathrm{L}_{\mathrm{k}} \leq 20.73$ & $\mathrm{~L}_{\mathrm{H}}>20.73$ \\
\hline $\mathscr{g}$ & & Diameter & $\mathrm{d}_{\mathrm{k}}<8.43$ & $8.43 \leq \mathrm{d}_{\mathrm{k}} \leq 9.95$ & $\mathrm{~d}_{\mathrm{H}}>9.95$ \\
\hline ह्र & G5 & Length & $\mathrm{L}_{\mathrm{k}}<18.24$ & $18.24 \leq \mathrm{d}_{\mathrm{k}} \leq 20.94$ & $t_{H}>20.94$ \\
\hline & & Diameter & $\mathrm{d}_{\mathrm{k}}<9.28$ & $9.28 \leq \mathrm{d}_{\mathrm{k}} \leq 10.72$ & $\mathrm{~d}_{\mathrm{H}}>10.72$ \\
\hline
\end{tabular}

hulled peanuts and by 465.13 and $455.3 \mathrm{~mm}^{2}$ for kernels, when the hull or kernel's mass is increased by $1 \mathrm{~g}$ for all tested varieties, respectively. The surface areas of hulled peanuts and kernels are very important characteristics in determining both volumetric and gravimetric heat transfer coefficients and in analyzing heat and moisture transfer during drying and frying processes.

3 Volume of an individual hull or kernel: The actual volume of a mixed sample was described geometrically by Akcali and Onur (1990) equation '7'. Some assumptions were applied to this model to be suitable for calculating the actual volume of an individual hull or kernel as previously described in methods. Actual volume $\mathrm{V}_{\text {act }}$ in $\mathrm{mm}^{3}$ and theoretical volume $\mathrm{V}_{\text {th }}$ in $\mathrm{mm}^{3}$ were correlated for hulled peanuts and kernels. The following linear form was found to be satisfied:

\section{Hulled peanuts:}

For SI1 variety $V_{\text {act }}=0.438 V_{\text {th }}+1.84 \quad R^{2}=0.73$

For G5 variety $\quad V_{\text {act }}=0.624 V_{\text {th }}+0.733 \quad R^{2}=0.89$

Peanuts Kernel:

For SI1 variety $\mathrm{V}_{\mathrm{act}}=0.3357 \mathrm{~V}_{\mathrm{th}}+0.135 \quad \mathrm{R}^{2}=0.79$

For G5 variety $\mathrm{V}_{\text {act }}=0.366 \mathrm{~V}_{\text {th }}+0.159 \quad \mathrm{R}^{2}=0.68$

Average hull or kernel diameters were also correlated to the actual volume of an individual hull or kernel as follow:

\section{Hulled peanuts:}

For SI1 variety: $V_{\text {act }}=0.035 d^{3}-0.6505 d^{2}+3.9769 d-6.317 \quad R^{2}=0.95$

For G5 variety: $\quad V_{a c}=0.0027 d^{3}-0.057 d^{2}+0.468 d+0.418 \quad R^{2}=0.92$

The $16^{\text {th }}$. Annual Conference of the Misr Society of Ag. Eng., 25 July, 2009 


\section{Peanuts kernel:}

For SI1 variety: $V_{\text {act }}=0.203 d+0.9874$

$$
\mathrm{R}^{2}=0.82
$$

For G5 variety $\quad \mathrm{V}_{\text {act }}=0.305 \mathrm{~d}+0.876$

$\mathrm{R}^{2}=0.85$

It is clear that due to the non-uniformity of hull shape, the fitted model was a polynomial of third degree, whereas, it tend to be linear for kernels due to its approximately uniform cylindrical shape.

4 Density and bulk density of hulls and kernels: The density and bulk density were evaluated as previously described in methods for hulls and kernels for both varieties studied. Correlations between bulk density " $\rho_{\mathrm{b}}$ " in $\mathrm{g} / \mathrm{mm}^{3}$ and voids space " $\varepsilon " \%$ for hulled peanuts and kernels were determined as shown in Fig.(7). The voids space and bulk density for both studied varieties were found to satisfy linear forms as follows:

\section{Hulled peanuts:}

For SI1 variety $\varepsilon=0.563 \rho_{\mathrm{b}}+0.114 \quad \mathrm{R}^{2}=0.85$

For G5 variety $\quad \varepsilon=0.183 \rho_{b}+0.384 \quad R^{2}=0.82$

Peanuts kernel:

For SI1 variety $\varepsilon=0.854 \rho_{b}+0.042 \quad R^{2}=0.88$

For G5 variety $\varepsilon=0.506 \rho_{\mathrm{b}}+0.10 \quad \mathrm{R}^{2}=0.81$

It is clear that the voids space ratio \% increased by 56.26 and $18.28 \%$ for hulled peanuts and by 58.35 and 50.61 for kernels, when the hull or kernel's bulk density increased by $1 \mathrm{~g} / \mathrm{mm}^{3}$ for all tested varieties respectively. Void space ratio is a valuable characteristic affecting air flow, heat and mass transfer, occupied volumes during handling, drying in packed beds and storage of peanut hulls or kernels.
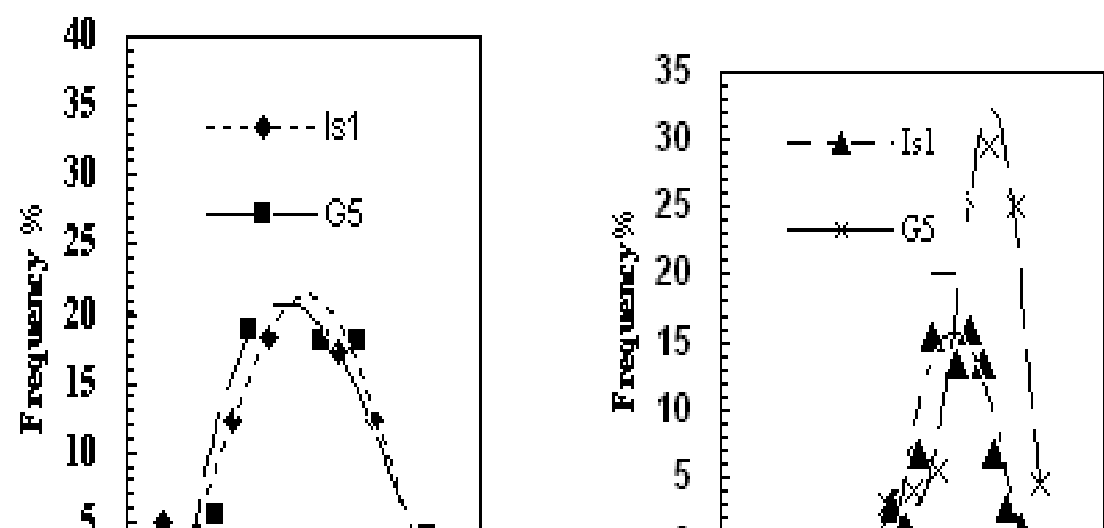


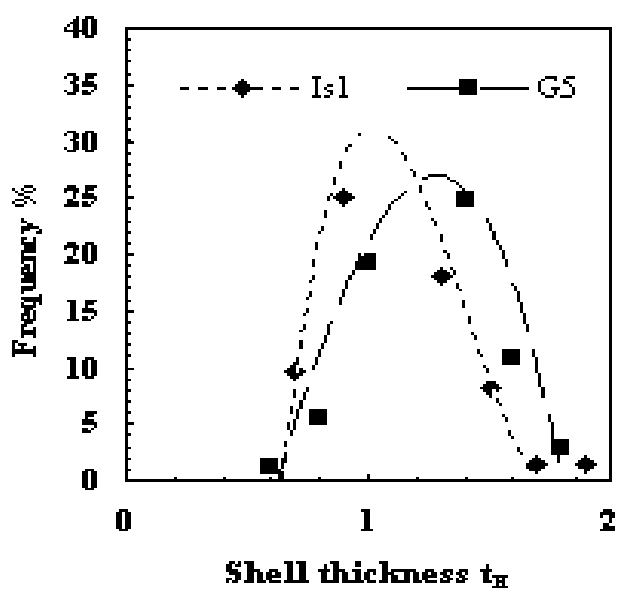

Fig.(4) Thickness frequency of hulled peanut shells.

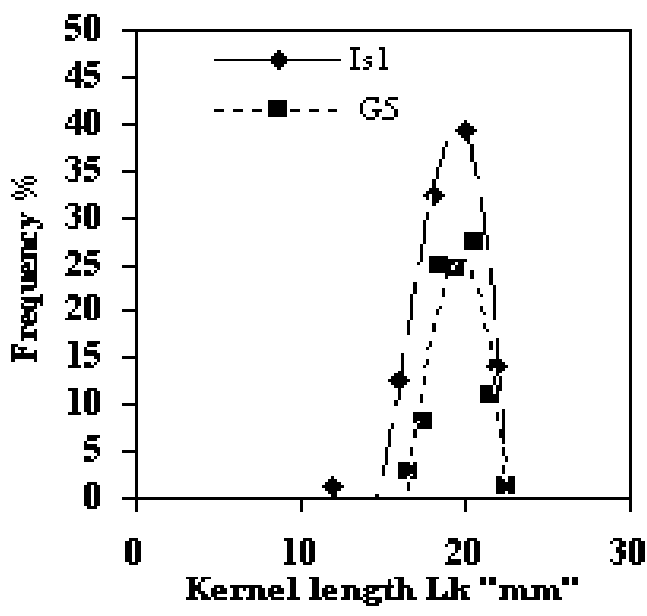

Fig.(5)Length frequency of kernels

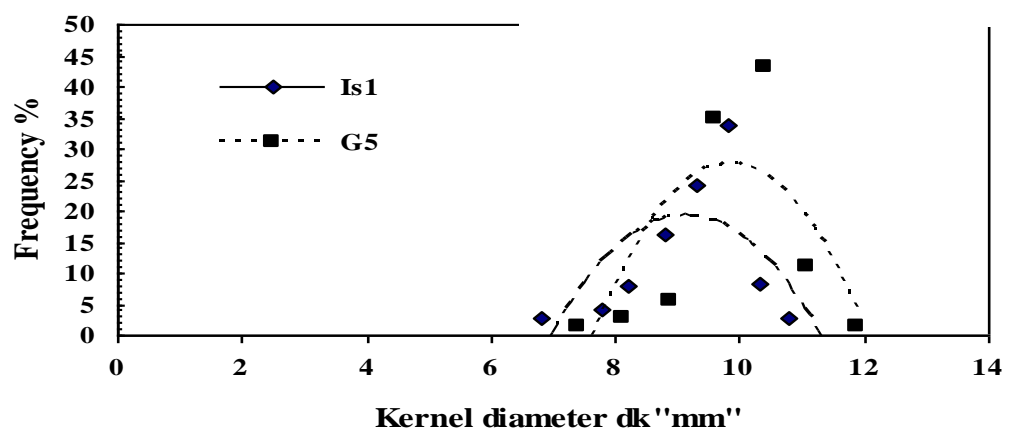

Fig.(6) Diameter frequency of kernels 


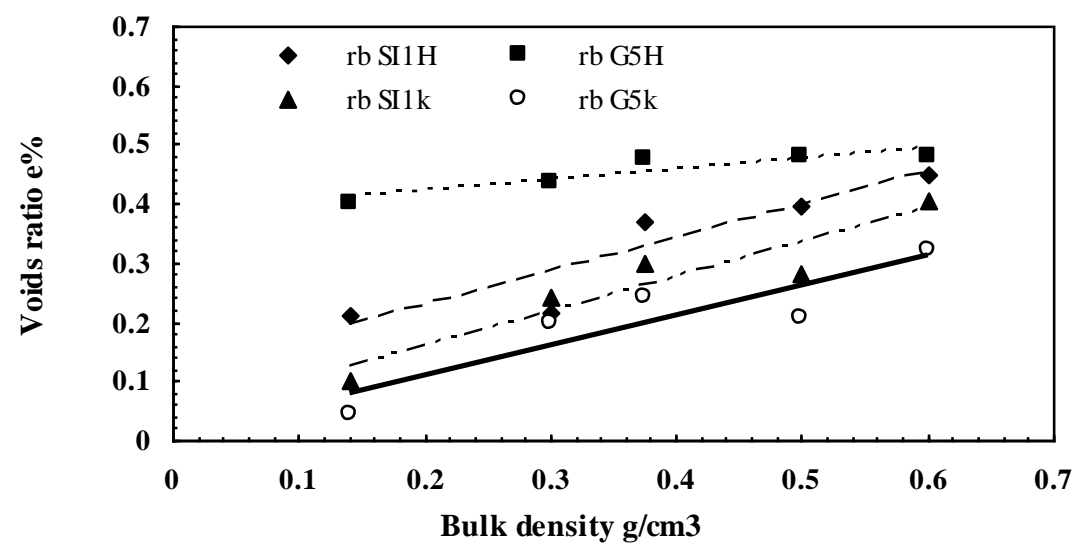

Fig. 7 ) Correlation between void space of hulled peanuts ,kernels and their bulk densitv of the two varieties studied.

\section{CONCLUSION}

Due to the lack of informations about physical properties of new created varieties of hulled peanuts, kernels and shells, and also owing to losses during harvesting, handling and the marked deterioration in quality of peanuts as a result of unsafe storage. This work was carried out to study some physical properties of two different Egyptian verities, namely: Ismailia1 "IS1" and Giza5"G5" that affect design and development of grading, storage, drying and frying machines such as mass, size, volume, void ratio, density, bulk density of both kernels and shells.

\section{From the present study we can conclude that:}

1-Average values of hull length, geometric diameter are 39.77, 39.81 and $14.33,15.61 \mathrm{~mm}$ for IS1 and G5 varieties respectively. Also average kernel length and diameter are ranged between 18.64-19.21, 19.38-19.38 $\mathrm{mm}$ and 9.05-9.4,9.92-10.2 $\mathrm{mm}$ for both tested varieties. The shell thickness had average of 1.17 and $1.24 \mathrm{~mm}$ for both studied varieties. It is clear that the G5 variety dimensions are slightly higher than that of the IS1 variety.

2- Peanuts were also classified into three classes with the help of hull or kernel dimension and the associated standard deviation. This classification is one of the necessary input data for design of grading machinery, and it can be used as a quality index. 
3- Correlations between hulls and kernels surface area and their weight were found to satisfy a linear form with coefficients of determinations of $0.77,0.56$ and $0.67,0.69$ for the hulled peanuts and kernels of the SI1 and G5 varieties respectively.

4- Average hull and kernel diameters in "mm" were also correlated to the actual volume of an individual hull or kernel. Due to the non-uniformity of the hull shape, the fitted models were third degree polynomials with coefficients of determinations of 0.95 and 0.92 for the SI1 and G5 varieties respectively, whereas, due to approximately cylindrical shape of kernels, the models fitted to kernels tend to be linear with coefficients of determination of 0.82 and 0.85 for the two studied varieties respectively.

5- Bulk densities in $\mathrm{g} / \mathrm{mm}^{3}$ of hulls and kernels were also correlated to the voids space $\%$. Linear forms were also found to be satisfied with coefficients of determinations of $0.85,0.82$ for the hulled peanuts and $0.88,0.81$ for kernels of both tested varieties respectively. Voids space ratio is a valuable characteristic affecting air flow, heat and mass transfer in drying of packed beds and occupied volumes in handling and storage of hulls or kernels.

\section{RFERENCES}

Akcali I.D. and Onur G. 1990 Physical properties of peanut in Turkey.Agr. Mech. In Asia, Africa and South America. 21(3)55-60.

ASAE 1994.Moisture measurement-peanut .Agric. Eng. YrBk. 5410Dec92St. Joseph Mich., :477-478.

Chakraverty,A.1972 Post harvest technology of cereals. Pulses and oil seeds Oxford Pub.Co.PVI, LTD,NewDelhi(C.F El-Raie et.al.1996)

El Raie A.E.S.1987 Properties of shelled corn related to mechanical separartion. Misr J. of Agric.Eng.,.4(1):36-51.

El Raie A.E.S.,N.A.Hendawy and A.Z.Taib.1996 A study of physical and engineering properties for some agricultural crops. Misr J. of Agric.Eng.,.13(1):211-236.

FAO,2008.Cultivated area of agricultural crops. www. org./docrep /v9998e/ v9998 Oe.htm. at 12/10/2008.

Hummeida M.A. and M.A.Ismail1989.Determination of equilibrium moisture content for two varieties of peanut. Agric. Mech. Asia and Latin America. 20(3): 53-58. of Agric.Eng.,12(1) 267-282. 
Matthews,J.1991 Progress in agricultural physics and engineering. Printed in U.K by Redwood Ltd,Melksham:215-216.

Mohsenin, N.N. 1970 Physical properties of plant and animal materials. Gordon and Brech Sc.Pub.,N.Y:889.

\section{الخواص الطبيعية لقرون وحبوب المبلي الفول السودانى}

د/ طارق حسين غانم * د/محمد احمد السيد شيتيوى** د/ أشرف كامل زعلوك**

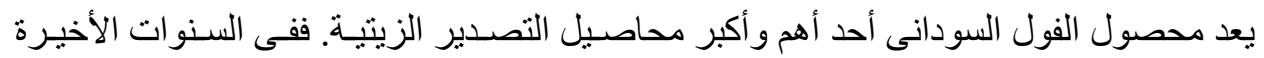

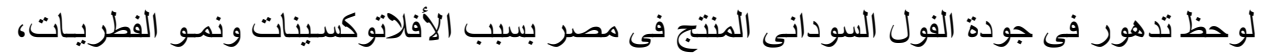

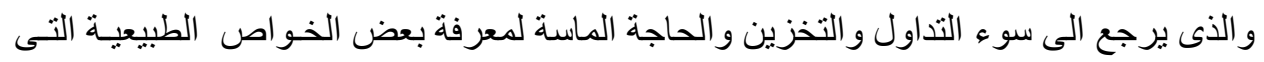

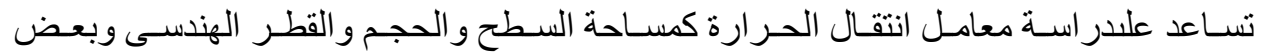
الخو اص المرتبطة بالتخزين كالكثافة الظاهرية و المسافات البينيةحيث يمكن الاستعانة بهذة النتائج

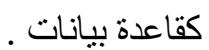

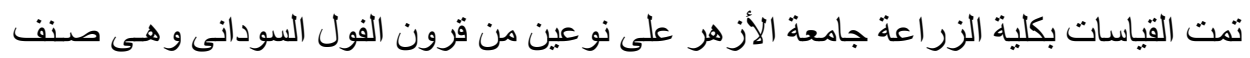

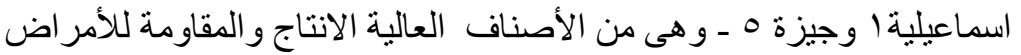
وكانت النتائج كلأنى: النئ

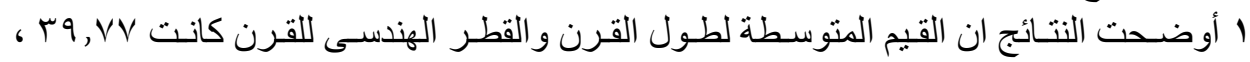

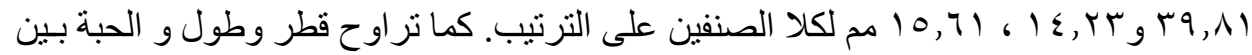
(

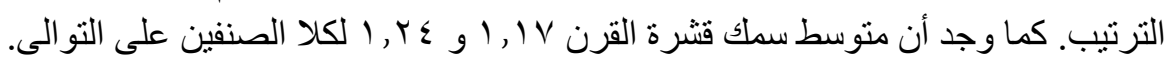

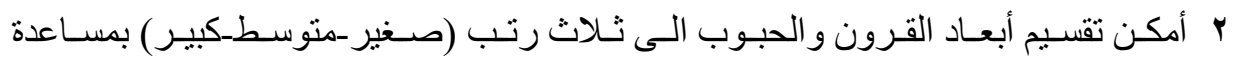

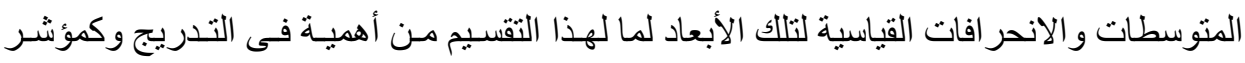

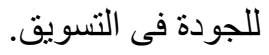

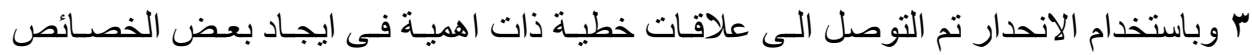

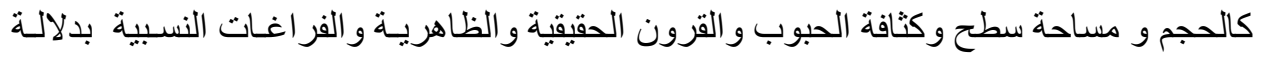

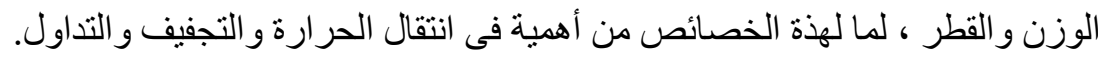

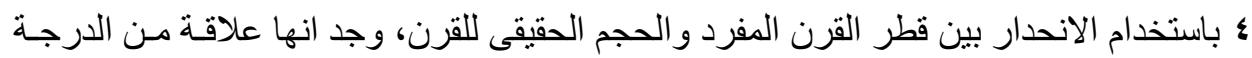

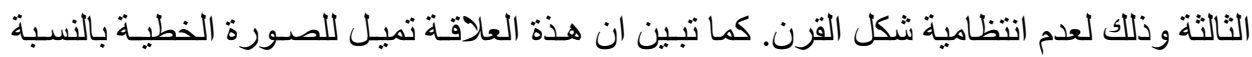

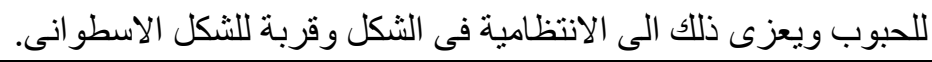

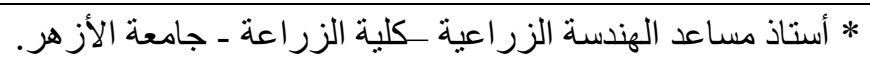
أمدرس الهندسة الزر اعية ـكلية الزر اعة - جامعة الأز هر. 